\title{
Correction to: Breast cancer risk in relation to plasma metabolites among Hispanic and African American women
}

\author{
Hua Zhao ${ }^{1}$ (1) $\cdot$ Jie Shen ${ }^{1}$. Steven C. Moore ${ }^{3}$ Y Yuanqing $\mathrm{Ye}^{1} \cdot$ Xifeng Wu $^{1} \cdot$ Francisco J. Esteva $^{4} \cdot$ Debasish Tripathy $^{2}$. \\ Wong-Ho Chow ${ }^{1}$
}

Published online: 1 June 2019

○) Springer Science+Business Media, LLC, part of Springer Nature 2019

\section{Correction to: Breast Cancer Research and Treatment https://doi.org/10.1007/s10549-019-05165-4}

In the original publication of the article, the sixth author name Krita A. Zanetti was mistakenly included as co-author. The corrected author group is given in the correction article. The original article has been corrected.

Publisher's Note Springer Nature remains neutral with regard to jurisdictional claims in published maps and institutional affiliations.

The original article can be found online at https://doi.org/10.1007/ s10549-019-05165-4.

Hua Zhao

hzhao2@mdanderson.org

1 Department of Epidemiology, The University of Texas MD Anderson Cancer Center, Houston, TX 77030, USA

2 Department of Breast Medical Oncology, The University of Texas MD Anderson Cancer Center, 1155 Pressler Street, Houston, TX 77030, USA

3 Divisions of Cancer Epidemiology and Genetics, National Cancer Institute, Bethesda, MD 20892, USA

4 Perlmutter Cancer Center at New York University Langone Health, New York, NY 10016, USA 